\title{
IDENTIDADES E CRENÇAS DO CONCLUINTE DO CURSO DE LETRAS DA UEG, CAMPUS JUSSARA
}

\author{
IDENTITIES AND BELIEFS OF STUDENTS WHO ARE MAJORING IN THE \\ LETRAS COURSE AT UEG, CAMPUS JUSSARA
}

DOI 10.20873/uft2179-3948.2021v12n1p370-394

Evandro Rosa de Araújo ${ }^{1}$

Resumo: O presente artigo tem o objetivo de discutir a identidade e as crenças de acadêmicos de Língua Inglesa concluintes do curso de Letras Português/Inglês da Universidade Estadual de Goiás (UEG), campus Jussara. A base teórica é uma pesquisa bibliográfica e qualitativa que utiliza dados colhidos em sala de aula durante o ano letivo de 2019. O pesquisador lança mão da metodologia de observação, com a aplicação de questionário e realização de entrevistas para a coleta dos dados, que serão analisados à luz das teorias da Linguística Aplicada ao ensino e aprendizagem de línguas. Com a presente pesquisa foi possível entender um pouco da identidade e crenças dos alunos da citada instituição. Teóricos como Barcelos (1995), Félix (1999), Lima (2000) e Silva e Figueiredo (2008), dentre outros, serviram de lastro para orientar e fundamentar os estudos.

Palavras-chave: ensino, identidade, crenças, língua inglesa.

Abstract: This article aims to discuss about identity and beliefs of English Language students, in the process of completing the Portuguese / English Letters course at the Universidade Estadual de Goiás (UEG). This is a bibliographic and qualitative research that uses data collected in the classroom context, during 2019. The researcher uses the methodology of observation, questionnaires and interviews to collect data that will be analyzed in the light of the theories of Applied Linguistics of language teaching and learning more specifically theorists who analyze beliefs and identity in language teaching and learning. With this research, it was possible to understand a little about the identity and beliefs of the students of the aforementioned institution. Theorists such as Barcelos (1995), Félix (1999), Lima (2000) and Silva e Figueiredo (2008), among others, served as the basis for the studies and consequently concretize the article.

Keywords: teaching, identity, beliefs, English language.

\section{Introdução}

\footnotetext{
${ }^{1}$ Professor de Língua e Literaturas de Língua Inglesa da Universidade Estadual de Goiás (UEG), mestre em Letras pela PUC-GO e Doutorando do Programa de Pós-Graduação em Letras e Linguística da Universidade Federal de Goiás (UFG). E-mail: evandrorj49@gmail.com
} 
$\mathrm{O}$ artigo tem como proposta discutir a identidade e as crenças de acadêmicos de Língua Inglesa da Universidade Estadual de Goiás (UEG), campus Jussara, com embasamento em teóricos como: Silva, K. (1994), Barcelos (1995), Félix (1999) e Silva e Figueiredo (2008), dentre outros. A pesquisa para o levantamento dos dados foi realizada no ano letivo de 2019 e teve como universo 15 (quinze) alunos do quarto ano. Os métodos utilizados foram: observação de aulas, aplicação de questionários e diálogo com teóricos da Linguística Aplicada que têm desenvolvido pesquisas na área de identidade e crenças no ensino e aprendizagem de Línguas. Conforme Barcelos (2000, p. 59), “[...] crenças são parte das nossas experiências e estão interrelacionadas com o meio em que vivemos".

A ideia da pesquisa nasceu primeiramente no contexto de sala de aula, mediante a observação da forma como os acadêmicos se portam diante da futura profissão que escolheram. Não é de todo descartável que se trata de visões conjecturais, pois, como diz Breen (1999, p. 124), muitas vezes os alunos são idealizados pelos professores, que,

[...] através do controle das práticas discursivas das aulas, através do uso de perguntas, explicações, instrução da linguagem produzida [...] imediatamente após sua articulação, $[\ldots]$ constroem os alunos primeiramente como participantes responsivos e passivos do discurso de sala de aula.

Essa visão panorâmica inicial, todavia, não deixa de evidenciar bastante a realidade circundante. Geralmente os alunos que decidem estudar licenciaturas chegam à academia com certas ideias pré-formadas e adquiridas nas escolas que estudaram anteriormente ou provenientes do ambiente familiar, dos amigos etc. A essas ideias soma-se o convívio com colegas no âmbito acadêmico, quando novas concepções vão sendo agregadas. Nesse sentido, Nunan (2000, p. 8) alerta que as crenças são "[...] contextualizadas dentro de interpretações de experiências de aprender línguas em contextos educacionais e sociais específicos. Sem conhecer o contexto, fica difícil dar significado mais profundo [...]”.

Por isso, quando se propõe a desenvolver estudos desta natureza, é fundamental que se conheça profundamente o contexto no qual a pesquisa será desenvolvida. Tal exigência devese ao fato de diferentes professores também possuírem ideias distintas e diversas sobre o que vem a ser a prática docente e o ensino e a aprendizagem de uma segunda língua. Essas ideias particulares ou pessoais podem perdurar durante certo tempo ou até mesmo indefinidamente, dependendo dos ambientes nos quais professores e alunos estão imersos. Talvez seja nesse sentido que Silva, I. (2005, p. 77) afirma:

As crenças na teoria de ensino e aprendizagem de línguas são essas ideias que tanto alunos, professores e terceiros têm a respeito dos processos de ensino/aprendizagem 
de línguas e que se (re) constroem neles mediante as suas próprias experiências de vida e que se mantêm por um certo período de tempo.

No mesmo sentido é comum o estabelecimento de discussões sobre o que vem a ser um bom professor e um bom aluno, ou a melhor forma de ensinar ou aprender uma língua estrangeira, dentre outras, como se confirma em Harmer (1999). A realização de tais discussões em sala de aula conduzirá a diferentes respostas, a maioria delas certamente calcada em identidades e crenças, pois a maior parte dos alunos teve poucas experiências de prática profissional. Na verdade, o que alimenta esse imaginário é a participação de alunos em algumas aulas de observação e regência na escola campo durante a realização da disciplina Estágio Supervisionado, o que certamente não garante aos acadêmicos respostas críticas e fundamentadas no amadurecimento das teorias e das práticas pedagógicas. Muitas dessas respostas, portanto, são conjecturas sobre o que são o ensino e a aprendizagem de línguas.

Por possuírem somente crenças ou hipóteses, talvez alguns alunos tenham uma noção fantasiosa do que vem a ser o ensino nas escolas da região, pois, como alerta Dewey (1933, p. 193), as crenças “[...] cobrem todos os assuntos para os quais ainda não dispomos de conhecimento certo, dando-nos confiança suficiente para agirmos, bem como os assuntos que aceitamos como verdadeiros, como conhecimento, mas que podem ser questionados no futuro".

Neste artigo, parte-se da hipótese de que as respostas de muitos acadêmicos às questões que lhes são postas ao longo do curso de Letras são, em sua maioria, oriundas do senso comum, embora os educandos estudem vários textos de teóricos que discutem identidade e crenças. $\mathrm{O}$ que se vê é que muitos ainda acreditam em afirmativas que podem ser consideradas falsas e que não estão calcadas em pesquisas e vivências mais duradoras em face do ensino e da aprendizagem do idioma. "É preciso uma investigação contextualizada das crenças. É necessário entender como as crenças interagem com as ações dos alunos e que funções elas exercem em suas experiências de aprendizagem dentro e fora de sala de aula" (TEIXEIRA DA SILVA, 2005, p. 155).

Quando esses acadêmicos começam a exercer suas funções docentes de forma definitiva, muitos tabus caem por terra, e é nesse momento que começam a ver a profissão de forma muito mais madura, apesar de ainda continuarem a agir segundo suas identidades e crenças. É por isso que Lima $(2009$, p. 3) alerta sobre a importância de uma formação que vá além dos bancos acadêmicos e reflita de forma sistemática sobre a postura do futuro profissional: 
Considerando o caráter social das crenças e o professor como o principal mediador na construção dos referenciais em uma segunda língua, a formação apropriada do profissional que leciona LEs [Línguas Estrangeiras] é fundamental para um trabalho de qualidade que forneça o aprendizado efetivo do idioma. A capacitação do docente e a reflexão sobre a presença das suas crenças nas metodologias adotadas contribuem também para a construção de um profissional crítico, reflexivo e que reconheça as dificuldades que permeiam o processo de ensino e aprendizagem da LE de forma a colaborar para que este aconteça de maneira prazerosa e eficiente.

As análises de teóricos da Linguística Aplicada, com relação ao presente tema, apontam que há muito a ser feito para que o acadêmico faça mais pesquisas e leituras sobre a prática docente e saia da universidade para o mercado de trabalho com uma visão mais próxima do que se entende hoje como os melhores caminhos para se ter uma aprendizagem eficiente e duradoura. Só assim ele conseguirá utilizar diferentes métodos de ensino e não ficar preso a uma única visão do complexo processo de ensino e aprendizagem da segunda língua.

Com base nessas questões, o presente texto divide-se em três partes: inicia-se com uma discussão sobre o perfil acadêmico e a formação da identidade dos alunos do curso de Letras da Universidade Estadual de Goiás (UEG), campus Jussara, análise orientada pelos estudos de Rajagopalan (1998), Coracini (2007) e Candau (2008), dentre outros. Na segunda parte, buscase entender as diferentes concepções de crenças sobre o ensino e a aprendizagem de línguas, à luz da Linguística Aplicada e de teorias de ensino-aprendizagem em geral, com base em teóricos como: Barcelos (2000), Silva, L. (2006) e Lima (2009), dentre entre outros que contribuíram de forma sistemática para esse campo de estudo. Por fim, analisam-se as respostas dos acadêmicos segundo as teorias acima explicitadas, buscando conhecer os posicionamentos deles e apresentando possíveis caminhos para que o curso de Letras da UEG, campus Jussara, consiga, em um futuro próximo, contribuir de forma mais sistemática para o aprimoramento da formação crítica dos educandos em face das concepções de identidade e crenças no ensino e aprendizagem de língua inglesa.

\section{Identidade e formação acadêmica}

A identidade do aluno do curso de Letras da UEG, campus Jussara, está em constante formação, visto que o acesso às novas tecnologias e a pronta relação com o outro vai sendo facilitada de forma gradual. Além disso, sabe-se que a interação e a assimilação de novas experiências são de fundamental importância para a formação docente. Do mesmo modo, como consequência de um mundo globalizado, diferentes visões vão abalando antigas convicções, em consequência do acesso facilitado às informações. De acordo com Rajagopalan (1998, p. 26), 
“[...] as identidades estão, todas elas, em permanente estado de transformação, ebulição. Elas estão sendo constantemente construídas. Em qualquer momento dado, as identidades estão sendo adaptadas e adequadas às novas circunstâncias que vão surgindo".

Nesse sentido, o ambiente no qual o educando está inserido contribui de forma sistemática para a construção de sua identidade como futuro professor. A cidade de Jussara, na qual se localiza o campus da UEG, lócus da pesquisa de que trata este artigo, está localizada na região Centro-Oeste, no noroeste do estado de Goiás, na Microrregião do Rio Vermelho. Limita-se com os municípios de Fazenda Nova, Britânia, Itapirapuã, Novo Brasil e Montes Claros. Sua população, segundo estimativas do Instituto Brasileiro de Geografia e Estatística (IBGE), era de 18.587 habitantes em 2018. Trata-se, portanto, de uma cidade pequena e distante dos grandes centros.

Outra informação relevante para o reconhecimento do ambiente no qual a pesquisa e desenvolveu é que a cidade de Jussara tem duas instituições de ensino superior: a UEG, que oferta os cursos de licenciatura em Letras Português/Inglês e respectivas literaturas, Pedagogia Modular e Matemática; e a União das Faculdades de Jussara (Unifaj), que oferece os cursos de bacharelado em Ciências Contábeis, Administração de Empresas, Tecnologia da Informação, Tecnologia em Gestão e Direito. Como já foi dito, trata-se de um município que está distante dos grandes centros, e cuja principal renda vem do mercado local e da agricultura.

O campus Jussara da UEG recebe alunos da microrregião, que trazem para o ambiente de sala de aula diferentes culturas, que vão sendo agregadas e assimiladas pelo grupo, construindo uma babel de identidades e falares que refletem no ensino e na aprendizagem de língua inglesa no contexto de sala de aula. "Passear pelos escombros de Babel significa vislumbrar o corpo poroso e disperso da heterogeneidade que constitui a linguagem e o sujeito, que ao mesmo tempo a revelam e a sufocam na aparência enganosa de uma unidade homogeneizante" (CORACINI, 2007, p. 45).

A interação desses alunos com os professores em sala de aula constrói um caldo de experiências que vai sendo gradativamente internalizado pelo grupo, modificando ou agregando as concepções de identidade de cada um. Os alunos trazem e levam valores e crenças que são entendidas em níveis diversos. De acordo com White (1999, p. 18), “[...] os alunos revisam e modificam suas expectativas específicas sobre ensino autônomo, à medida que vão ganhando experiências no novo contexto". Nesse sentido, o ensino de línguas precisa ser dinâmico, 
cabendo ao professor a responsabilidade de ensinar o idioma com foco na diversidade de culturas que a instituição reúne.

Do mesmo modo, ao pesquisar o contexto de ensino e aprendizagem da região, o que se evidencia é que no município de Jussara existem cinco escolas estaduais de ensino fundamental e médio e seis escolas municipais exclusivamente de ensino fundamental, nas quais os alunos do curso de Letras fazem suas pesquisas, experiências, entrevistas e realizam o Estágio Supervisionado de Língua Inglesa. Essas atividades acarretam também uma socialização de saberes e experiências diversas que influem nas concepções de ensinar e aprender idiomas.

O foco na identidade, no âmbito da educação, revela-se indispensável. Qualquer teoria
pedagógica precisa examinar de que modo espera alterar a identidade do/a estudante.
O fim do ensino é que o/a aluno/a aprenda a atribuir significados e a agir, socialmente,
de modo autônomo. Essa perspectiva exige a aprendizagem de saberes e habilidades,
a adoção de valores, bem como o desenvolvimento da identidade pessoal e da
consciência de si como um indivíduo que, inevitável e continuamente, deverá julgar
e agir (MOREIRA; CÂMARA, 2008, p. 39).

Deve haver, portanto, uma relação direta do educando com todas as fases de sua futura profissão. No que diz respeito ao futuro professor de Língua Inglesa da UEG, campus Jussara, vivenciar o ensino nas escolas da região dá-lhes a oportunidade de ministrar aulas e desenvolver projetos e oficinas com os alunos do ensino fundamental e médio e conhecer um pouco da realidade de sua futura profissão. $\mathrm{O}$ aprendizado gerado durante essas atividades vai além das teorias subscritas nos livros, pois permite também que se partilhe e receba crenças que há muito tempo estão cristalizadas no imaginário dos professores e alunos da escola campo. Nesse sentido, "[...] os alunos devem ser encorajados a discutir e explorar as relações entre crenças individuais e as ações sobre aprendizagem de línguas e os contextos sociais onde elas ocorrem" (BENSON; LOR, 1999, p. 14).

Mas o que se pode observar analisando as respostas dos alunos concluintes do curso de Letras do campus Jussara da UEG - constantes na última parte deste artigo -, é que eles tendem a construir uma visão de que o ensino de Inglês, tanto nas escolas de ensino médio quanto superior, é utópico, pois muitas vezes não conseguem ver de imediato a importância de se aprender esse idioma. Surgem, assim, questionamentos do tipo: por que aprender e ensinar inglês no interior? Por que devo aprender a falar a língua, se nunca terei oportunidade de usála? Por isso, o professor precisa estar consciente de seu papel e da importância daquilo que ele faz no contexto da sala de aula. Ele precisa apresentar aos alunos justificativas e razões pelas quais aprender a língua e a cultura do outro é necessário até mesmo para melhor valorizar a cultura local. 
É nesse sentido que Totis (1991, p. 15) afirma:

Cabe ao professor de línguas a tarefa de conscientizar os alunos e alguns de seus colegas da relevância do ensino da língua estrangeira para a formação do indivíduo, mostrando-lhes a dimensão de ordem educacional inerente a essa experiência - o aluno está de posse de uma ferramenta que será usada para se comunicar, está exposto à descoberta e valorização do outro nas suas relações como ser social, podendo da mesma forma compreender a diferença de costumes entre os povos, adquirindo uma consciência crítica sobre sua própria cultura e valorizando-a também.

Agindo dessa forma, é possível vislumbrar um horizonte no qual a aprendizagem será cada vez mais eficiente no seio da universidade, assim como das escolas locais, nas quais a aprendizagem da língua inglesa possa ser entendida de forma consciente e alcance a significância necessária aos dias de hoje. Como diz Benevides (2005, p. 88), “[...] a construção dos saberes está diretamente ligada ao contexto social, ao tempo, às condições materiais e aos aspectos sócio-histórico-culturais que fazem parte integrante do processo pedagógico".

Com relação à sua própria identidade, o curso de Letras da UEG, campus Jussara, nasceu do esforço conjunto de uma sociedade que ansiava por ter na região um centro de formação universitária que pudesse atender de forma integral os professores que ainda não tinham formação superior na área em que atuavam e os alunos que terminavam o ensino médio e queriam cursar uma licenciatura e muitas vezes tinham de mudar de sua região de origem para outras cidades, deixando para trás família, amigos, raízes e história. Esses alunos buscavam estudos em instituições distantes de seus habitats, pois reconheciam que a formação universitária era fundamental para suas vidas. É nesse sentido que Peixoto (2004, p. 62) pontua:

Na sociedade contemporânea, a ciência e a técnica produzidas ou apropriadas pelo
indivíduo não servem apenas para que este obtenha um emprego, mas são relevantes,
sobretudo porque tornam mais rica uma coletividade nacional, assegurando-lhe a
capacidade de se modernizar e de competir na cena internacional. [...] em um país
marcado pela desigualdade, pela insegurança, por ameaças ao ambiente e tantos outros
problemas, não seria esta a mais rara e preciosa entre todas as riquezas?

A citação reflete o sentimento do estudante que queria e compreendia o valor do ensino superior em sua vida. Mas aqueles que aceitavam o desafio de permanecer em Jussara tinham de fazer uma seleção (vestibular) em Anicuns, cidade de Goiás ou Iporá, dentre outras que possuíam faculdade na região. Por isso, tinham de se deslocar diariamente para receber a formação desejada. Essas viagens eram longas e muito perigosas, haja vista que os veículos utilizados no transporte sofriam desgastes decorrentes do percurso realizado de forma intermitente, o que acarretava acidentes e casos de fatalidades. Essas experiências não deixavam de influenciar a formação da identidade dos futuros professores. 
Vivenciando esse contexto de angústias e desafios, o aluno, futuro profissional que buscava formação universitária, acabava desistindo do curso, ou criava expectativas pessimistas sobre sua futura profissão. Sobre isso, a citação a seguir traz uma reflexão interessante:

Em seu processo de formação, o universitário se depara com um conjunto de desafios e rupturas, inerentes à vida universitária e seu período de desenvolvimento. Entre eles, pode-se destacar a escolha de curso e carreira, adaptação à transição acadêmica, atendimento a novas exigências cognitivas, de estudo e desempenho, gestão de tempo. O gerenciamento do conjunto de tarefas solicitadas pode estimular o desenvolvimento ou, se associado a pouco apoio, gerar diferentes níveis de dificuldades. Tais níveis podem desencadear eventos como opção ou reopção de curso inadequada, reprovação ou, mesmo, a evasão (JOLY et al., 2005, p. 180).

É de domínio geral que a identidade do futuro professor começa a ser delineada logo no início de seus estudos, como também é fruto da convivência e dos desafios enfrentados ao longo de sua formação.

Depois de longos anos assistindo o deslocamento diário dos jovens universitários, Jussara pôde finalmente contar, depois de muitas lutas, com a implementação de uma instituição superior na cidade. Em 21 de fevereiro de 1999, foram implantadas as primeiras turmas dos cursos de Letras Português/ Inglês e respectivas literaturas, Matemática e História, na UEG, campus Jussara.

À frente da direção do campus universitário estava o professor José Izecias de Oliveira, que contratou professores de diferentes cidades do estado de Goiás. Mas como esses docentes permaneceram morando em suas cidades de origem, o deslocamento frequente para Jussara e a distância que tinham de percorrer acabaram levando muitos deles a abrirem mão do emprego. Tal situação acarretou uma alta rotatividade de professores, o que comprometia bastante a formação dos discentes. Essa situação só foi resolvida com a formação dos alunos das primeiras turmas do campus Jussara, que, por meio de aprimoramentos constantes e implantação da educação continuada, retornaram à instituição como professores.

A UEG firmava, assim, sua missão de formar professores comprometidos com a educação pública e privada de qualidade, conforme consta em seus documentos oficiais (UEG, 2009). Não se desconhece, todavia, que esse é um processo contínuo que precisa de constantes reflexões para que o curso pense sobre a formação do aluno contemporâneo de forma integral, formando um profissional apto para transformar o espaço que ocupa.

Repensar a escola hoje é, antes de mais, trazer para o cenário educativo este "vértice perdido", sublinhando a importância de uma participação que não se esgota no nível profissional, nem no plano do Estado. É procurar encontrar novas respostas para um velho problema (NÓVOA, 1998, p. 20). 
Com relação ao curso de Letras, conforme revela seu estatuto, ele sempre buscou “"[...] formar professores reflexivos e antenados com seu tempo" (UEG, 2009), estabelecendo parcerias e consolidando sua importância na região como formador de professores de Línguas e Literaturas. Além disso, é preocupação dos professores que os alunos saibam refletir de forma constante sobre suas futuras práticas pedagógicas, que devem ultrapassar o contexto da sala aula.

Dessa forma, observando o percurso de evolução da universidade ao longo dos últimos 15 anos, mais especificamente do Departamento de Letras, na área de ensino de Língua Inglesa, constatou-se que os alunos chegam com uma ideia do que é aprender e ensinar língua estrangeira e, ao findar do curso, a grande maioria muda de posicionamento. "Neste sentido, podemos inferir que nós somos seres criados pelos outros, isso faz-nos refletir que todas as formas de interação podem ser responsáveis pela criação de nossa identidade, inclusive e com grande ênfase no ambiente escolar" (BURGEILE, 2014, p. 34).

Por essa razão, refazer o percurso histórico da UEG, campus Jussara, foi necessário para traçar o perfil do aluno do curso de Letras da instituição nos dias de hoje. A universidade conta com uma clientela heterogênea, composta por estudantes de diferentes idades e por alunos que interromperam seus estudos e retornaram à universidade para conclúí-los, todos oriundos de Jussara ou de cidades circunvizinhas. Muitos deles vêm de escolas públicas e geralmente não tinham perspectivas quanto ao ingresso em um curso superior. A maioria é do sexo feminino, havendo, portanto, poucos rapazes em cada sala, seguindo a média nacional, como pode ser confirmado na citação a seguir.

Existe uma predominância de alunos do sexo feminino (73\%), proporção esperada,
uma vez que o magistério de $1^{\circ}$ e $2^{\circ}$ graus é profissão tradicionalmente feminina. A
presença feminina nos cursos nas áreas de humanidades é fenômeno comum no Brasil,
já evidenciado em pesquisas como as de Pastore (1972), Normando e Leite (1977),
Ficou constatado também que a proporção de mulheres nos cursos de Licenciatura é
ainda muito acentuada (VEIGA, 1989, p. 30).

O perfil dos sujeitos que constituem o universo desta pesquisa pode ser conferido na Tabela a seguir.

Tabela - Características dos concluintes do curso de Letras da UEG, campus Jussara, participantes da pesquisa

\begin{tabular}{l|l|l|l|l}
\hline PARTICIPANTES & \multicolumn{1}{|c|}{ SEXO } & IDADE & \multicolumn{1}{|c}{$\begin{array}{c}\text { REGĨ̃O DE } \\
\text { ORIGEM }\end{array}$} & \multicolumn{1}{c}{$\begin{array}{c}\text { ESCOLA PÚBLICA / } \\
\text { PRIVADA }\end{array}$} \\
\hline ALUNO -1 & FEMININO & 20 & NOVO BRASIL & PÚBLICA \\
\hline ALUNO -2 & FEMININO & 21 & MONTES CLAROS & PÚBLICA \\
\hline ALUNO -3 & FEMININO & 25 & JUSSARA & PRIVADA \\
\hline ALUNO -4 & FEMININO & 32 & JUSSARA & PÚBLICA \\
\hline
\end{tabular}




\begin{tabular}{l|l|l|l|l}
\hline ALUNO -5 & FEMININO & 33 & MONTES CLAROS & PÚBLICA \\
\hline ALUNO -6 & FEMININO & 25 & SANTA FÉ & PÚBLICA \\
\hline ALUNO -7 & MASCULINO & 28 & FAZENDA NOVA & PÚBLICA \\
\hline ALUNO -8 & FEMININO & 21 & JUSSARA & PRIVADA \\
\hline ALUNO -9 & FEMININO & 26 & JUSSARA & PÚBLICA \\
\hline ALUNO -10 & FEMININO & 24 & NOVO BRASIL & PÚBLICA \\
\hline ALUNO -11 & MASCULINO & 22 & ITAPIRAPUAि & PÚBLICA \\
\hline ALUNO -12 & FEMININO & 27 & JUSSARA & PÚBLICA \\
\hline ALUNO -13 & FEMININO & 29 & JUSSARA & PRIVADA \\
\hline ALUNO -14 & FEMININO & 24 & BRITÂNIA & PÚBLICA \\
\hline ALUNO -15 & FEMININO & 37 & BRITÂNIA & PÚBLICA \\
\hline
\end{tabular}

Fonte: Elaborada pelo autor, com base nos dados da pesquisa.

Nas dinâmicas de início de ano com os calouros, quando questionados sobre suas expectativas sobre o curso que escolheram, poucos dizem que fizeram a seleção por vocação. Afirmam que queriam fazer outros cursos, mas que, diante da realidade socioeconômica e da falta de preparação para passar em outros cursos oferecidos por universidades públicas e que julgam ser suas reais vocações, acabaram tendo de fazer uma licenciatura. Indagados sobre o motivo que os leva a escolher justamente Letras, entre as licenciaturas que a universidade oferece, a resposta da maioria deles é a de que foram motivados pelo número de concorrentes inscritos no processo seletivo. Poucos são os alunos que respondem ter ingressado no curso para serem professores. Geralmente essa é a realidade.

Atualmente o curso de Letras possui três turmas no período noturno, formadas por alunos que geralmente trabalham em confecções, lojas e no comércio local em geral, estabelecimentos que exigem de seus funcionários oito horas de trabalho diárias. Os alunos, portanto, chegam à UEG, campus Jussara, depois de suas rotinas de trabalho e estudam até às 22h30, quando retornam para suas casas. Resta, assim, pouco tempo para o desenvolvimento dos trabalhos ou para participar de grupos de estudos em outros horários.

\footnotetext{
Hoje é possível perceber a presença de alunos de diferentes estratos sociais nos meios universitários. Uma boa parte dos alunos arca com o ônus de seu próprio sustento, conciliando o trabalho com a frequência aos cursos de formação de professores. Trazem todas as dificuldades que envolvem a complexa articulação da condição de trabalhador e estudante (VEIGA, 1989, p. 28).
}

A UEG não pode fechar os olhos a essa realidade, por isso, o aluno que ingressa no curso de Letras precisa receber uma formação de qualidade, mas que esteja em consonância com suas limitações: pouco tempo disponível para leituras e para participar de eventos, cursos de extensão e/ou atividades extraclasse em geral. A realidade supracitada serve para que se entenda um pouco a construção da identidade desses acadêmicos que buscam no curso de Letras a possibilidade de mudança da realidade na qual estão inseridos. Pensando assim, o professor universitário terá uma missão significativa nesse processo, qual seja a de motivar e facilitar a 
aquisição do conhecimento que o educando precisará para o desenvolvimento de sua futura profissão.

É necessário que o professor seja ponte entre o conhecimento disponível e as estruturas cognitivas, culturais e afetivas dos educandos. Sobre essas bases é que é preciso reconstruir a função docente, aceitando o desafio de uma nova perspectiva para a profissionalização (CUNHA, 2007, p. 18).

O aluno, ao longo de quatro anos de curso, vai construindo sua identidade. Isso ocorre justamente por causa das afinidades com os colegas, dos laços que criam entre si, da relação com professores e disciplinas variadas que estuda ao longo do curso etc. Essas relações quase sempre acontecem não por acaso, mas pelo gosto do acadêmico de conhecer e se aproximar de forma gradativa das pessoas com as quais tem afinidade.

A identidade construída pode ser pessoal ou coletiva. A primeira é configurada pela história e experiência pessoal e implica um sentimento de unidade, originalidade e continuidade, enquanto que a segunda é uma construção social que se processa no interior dos grupos e das categorias que estruturam a sociedade e que conferem à pessoa um papel e um status social. A identidade profissional configura-se como uma identidade coletiva (BRZEZINSKI, 2002, p. 8).

O que tem sido observado ao longo dos anos no curso de Letras da UEG, campus Jussara, são parcelas de alunos que, quando se referem à prática de ensinar línguas, embasam suas falas: no senso comum; nos discursos de professores de Inglês aposentados, e que por isso vivenciaram situações diferentes das atuais; em experiências de profissionais que estão desmotivados com a profissão; ou em relatos de pessoas que não conhecem bem a docência, dentre outros.

Mas também há, entre os futuros professores de Inglês, aqueles que são extremamente motivados, que desejam modificar situações e romper paradigmas. E a universidade trabalha para esses educandos que querem ir além da realidade circundante. Segundo Barcelos (2013, p. 9), “[...] o desvelamento das crenças de professores e alunos permite uma melhor adequação de objetivos, conteúdos e procedimentos, e consequentemente chances de maior eficácia do processo de ensino e aprendizagem".

Considerando que o curso de Letras, por meio de suas disciplinas, apresenta teóricos de diferentes vertentes aos acadêmicos, há de se indagar: será que o aluno do quarto ano conseguirá diferenciar tais teorias e agir em sua prática profissional futura de forma competente e menos desligada do senso comum? Tudo indica que as hipóteses aqui levantadas tendem a ser confirmadas, tendo em vista as evidências apresentadas até aqui. Então, com base nos questionamentos levantados, o próximo tópico apresenta aspectos da formação do futuro professor e como as crenças tendem a contribuir ou atrapalhar o trabalho docente. 


\subsection{Crenças e suas implicações na formação do professor de Inglês}

Antes de discorrer sobre o que são crenças e formação do professor, vale a pena salientar a importância da educação de qualidade. Ensinar Língua Inglesa, ou qualquer outra disciplina, é uma missão que precisa ser executada de forma criteriosa, buscando o melhor caminho para atingir resultados satisfatórios. O ensino no Brasil tem dado mostras de pouco rendimento, e muitas são as pesquisas que discutem e apontam caminhos para a melhoria da qualidade das aulas e do processo de ensino e aprendizagem como um todo. Por isso, como afirma Libâneo (2006, p. 7), ainda há muito a ser feito:

O Brasil, país capitalista periférico, possui graves problemas educacionais e historicamente tem procurado resolvê-los, importando modelos e reflexões pedagógicas desenvolvidos em países centrais com características sociais e em estágios de desenvolvimento econômicos completamente diversos dos seus.

Nesse sentido, o que se nota é que os investimentos em educação ou são insuficientes ou a corrupção impede que sejam aplicados de forma eficiente. O noticiário de televisão, jornais, revistas, internet e outros meios de comunicação colocam em evidência a crise em que a educação brasileira está mergulhada. A educação tem sido foco de matérias que mostram escolas de diferentes níveis de ensino serem depredadas; alunos sendo alvo de violências, professores colocados em situação de risco; indisciplina em sala de aula; sucateamento de instalações e falta de espaço, o que desmotiva não somente o professor, mas também o aluno do ensino médio, levando-o a não querer investir em uma licenciatura, e o universitário que está em vias de formação, que se sente desestimulado em face de sua futura carreira.

Dessa forma, em meio a esses problemas recorrentes nas instituições educacionais de todos os níveis, o que se percebe é que o aluno evidentemente construirá hipóteses e formará em seu imaginário diferentes concepções de como o ensino poderia ser melhor. Esboçam as escolas dos sonhos, o aluno ideal, os métodos mais eficientes, o espaço adequado, o respeito de todos pela profissão e uma infinidade de idealizações que vão sendo gradativamente cristalizadas no imaginário de cada um, constituindo assim uma gama de crenças e conjecturas de como o ensino de línguas poderia ser. De acordo com Barcelos (1995, p. 40), trata-se de um

[...] conhecimento intuitivo implícito (ou explícito) dos aprendizes, constituído de crenças, mitos, pressupostos culturais e ideais sobre como aprender línguas. Esse conhecimento compatível com sua idade e nível sócio-econômico é baseado na sua experiência educacional anterior, leituras prévias e contatos com pessoas influentes. 
Ao ingressar no curso, o aluno traz certas ideias pré-fabricadas, que tendem a desaparecer ou a se perpetuar até se formar. Duas concepções são mais facilmente observáveis nesse contato do acadêmico com o meio universitário: as crenças alheias e as pessoais, que influirão de forma sistemática em sua formação, levando-o a vivenciar momentos de profunda angústia ao longo do curso e mesmo depois de concluí-lo. Na concepção de Benson e Lor (1999, p. 464), as crenças “[...] referem-se ao que o aprendiz acredita que são os objetos e processos de aprendizagem" e ao que "[...] -acredita ser verdadeiro sobre esses objetos e processos, dada uma certa concepção do que eles são". Assim, o acadêmico muitas vezes constrói visões estereotipadas da prática de ensinar e aprender línguas.

Dessa maneira, é imprescindível conscientizar o aluno sobre o que são crenças, em confronto com o que é real e fundamental. Isso é necessário para que o futuro professor saiba exatamente por quais razões estará usando determinada abordagem, e não porque alguém lhe disse que determinadas concepções de ensino seriam mais eficientes. Sabe-se que as salas são heterogêneas e ensinar língua inglesa no atual contexto é ter domínio de teorias que guardam uma profunda relação com a prática e saber aplicá-las no momento certo. Libâneo (2006, p. 19) pontua que

[...] uma boa parte dos professores, provavelmente a maioria, baseia sua prática em prescrições pedagógicas que viraram senso comum, incorporadas quando de sua passagem pela escola ou transmitidas pelos colegas mais velhos; entretanto, essa prática contém pressupostos teóricos implícitos. Por outro lado, há professores interessados num trabalho docente mais consequente, professores capazes de perceber o sentido mais amplo de sua prática e de explicitar suas convicções.

Dentro de uma sala de aula, portanto, se perguntar aos alunos suas preferências sobre como o professor de Inglês deveria ensinar, vão surgir diferentes ideias, a grande maioria delas calcada em crenças sobre o que eles acham que seria legal, divertido etc. Todavia, eles ignoram que existem teorias que estudam esse processo de aquisição de línguas e que, para dar certo, para alcançar resultados positivos, é importante o casamento da teoria com a prática. É recomendável que se tenha em mente também que uma mesma abordagem de ensino não irá agradar a todos, o mesmo ocorrendo com o conteúdo, a voz do professor ou o perfume que usa etc.

Assim, quando se fala na educação em geral, diz-se que ela é uma atividade onde
professores e alunos, midiatizados pela realidade que apreendem e da qual extraem o
conteúdo de aprendizagem, atingem um nível de consciência dessa mesma realidade,
afim de nela atuarem, num sentido de transformação social (LIBÂNEO, 2006, p. 31).

É fundamental levar o aluno a perceber que, para ensinar e aprender língua inglesa, o professor não precisa dar show de aula todos os dias. Estudar é um processo sério e que exige 
comprometimento da escola, do professor, do aluno e de sua família. Já está mais do que na hora de deixar de ver o ensino como um laboratório de experimentação e colocar em prática o que os estudos têm apontado como o método mais eficiente. Evidentemente as motivações do professor e do aluno contam muito, mas elas são apenas parte do processo.

O que não se pode é perder tempo pensando que, se a aula tivesse sido ministrada com música, os alunos teriam prestado mais atenção; que a aula não ficou boa porque o professor nunca morou fora do país; que ficou ruim porque o professor fala quase só em português, não usa o inglês. Todas essas conjecturas, em sua grande maioria, não refletem a eficácia de um ensino de inglês. Como Almeida Filho (1999) aponta, muitas crenças podem, sim, contribuir para o ensino de línguas, mas outras, não. Existem definições que soam absurdas, e hoje sabese que o senso comum pode ou não ajudar o processo de ensino-aprendizagem. Ou seja, as crenças não podem ser deixadas de lado, haja vista que elas permeiam a filosofia do professor, e são elas que ajudam o profissional em sua tomada de decisão inicial; o que não se pode é acreditar que elas são definitivas e pensar que bastam para o trabalho docente.

Muitos professores agem de uma determinada forma porque tiveram professores que agiam assim; por isso, simplesmente reproduzem o que eles faziam, o que é um equívoco, já que não foram investigados os métodos e as teorias nas quais eles se apoiavam para conduzir suas aulas daquela maneira. O conteúdo, como se sabe, é fixo, mas a maneira como vai ser aplicado pode obedecer a infinitas metodologias. Uma determinada maneira de ensinar de um professor muitas vezes não se ajusta a outro, pois cada profissional tem um perfil e, por isso, copiar a receita de determinado professor pode não ser o melhor caminho.

O ideal é que o docente assuma a postura de um pesquisador empírico, experimentando diferentes abordagens, para assim encontrar, entre as muitas teorias sobre a aquisição de uma segunda língua, aquela que se enquadra a seu perfil e ao de seus alunos. Não adianta querer trabalhar a música como um recurso didático se as habilidades do professor nessa área forem limitadas, ou se ele não apreciar música.

O professor precisa construir seu perfil, e as crenças e as teorias são importantes nesse processo. O que não deve ser ignorado é que, mesmo conhecendo diferentes teorias de ensino e aprendizagem, muitos professores ainda seguem suas próprias crenças ao planejarem suas aulas, ignorando que diferentes pessoas aprendem de diferentes formas. Agindo assim, esses professores acabam influenciando nas crenças e identidades dos alunos. A esse respeito, diz Ianesko (2013, p.120): 
[...] percebemos a grande influência que as atitudes do professor em sala de aula, assim como postura profissional, opiniões, costumes têm sobre seus alunos, em todos os níveis de ensino. Pode-se concluir que os professores ajudam ou não a criar a identidade dos alunos e, com certeza, ajudam a enfatizar as suas crenças.

As pesquisas relacionadas às crenças e aos mitos no ensino de línguas no Brasil são relativamente recentes. Começaram por volta da década de 1990, foram se expandindo gradativamente e hoje tem-se uma quantidade significativa de trabalhos publicados nesta área.

No Brasil, estudos sobre crenças começaram a ganhar força com Leffa (1991), Almeida Filho (1999), Barcelos (1995), para citar alguns. Foi na conferência da Associação Internacional de Linguística Aplicada, em 1993, que, pela primeira vez no Brasil, houve um simpósio sobre crenças de aprendizagem de línguas e, mais tarde, no mesmo ano, foi publicado um volume do periódico System, dedicado a crenças sobre aprendizagem de línguas (IANESKO, 2013, p. 121).

A partir de então, os estudos e reflexões sobre o tema não pararam, o que pode facilitar o contato dos professores com diferentes posicionamentos diante desse tema tão recorrente. Feitas as considerações sobre crenças e a aproximação dessas com o universo da pesquisa, na próxima seção analisam-se os dados recolhidos ao longo da pesquisa.

\subsection{Entendendo a prática à luz da teoria}

Esta parte do artigo tem o objetivo de analisar as respostas dos alunos do quarto ano do curso de Letras da Universidade Estadual de Goiás (UEG), campus Jussara, e está dividida em duas seções. A primeira mostra a metodologia utilizada na coleta e análise dos dados, enquanto a segunda apresenta os resultados da pesquisa propriamente dita, com exposição dos questionamentos e análise dos dados colhidos durante a aplicação da pesquisa.

\subsubsection{Metodologia de aplicação}

A presente pesquisa lançou mão de um questionário aberto e entrevistas com gravação das respostas de 15 (quinze) acadêmicos concluintes do curso de Letras Português / Inglês da UEG, campus Jussara. O material foi colhido entre os dias 9 a 14 de setembro de 2019, no período de intervalo das aulas, para não comprometer a dinâmica rotineira da instituição, e apoiou-se na metodologia de manipulação de dados citada por Almeida Filho (1999) e Barcelos (2001), que concebe o questionário aberto e a gravação de entrevista como importantes meios para se conhecer a realidade circundante.

O pesquisador apresentou-se aos alunos e explanou sobre sua intenção de desenvolver a pesquisa. De forma voluntária, todos os 15 integrantes da turma ofereceram-se para participar 
e preencheram Termo de Consentimento Livre Esclarecido (TCLE). A identificação dos alunos foi feita numericamente (Aluno 01, Aluno 02 etc.), visando assim resguardar suas identidades. Foi aplicado aos alunos um questionário com as seguintes questões:

1) Como você tem visto sua futura profissão?

2) Você se sente preparado para ensinar Língua Inglesa?

3) Quais crenças você acha que possui, em vias de terminar a faculdade?

4) O que é um bom professor de Inglês?

5) Como aprender inglês de forma eficiente?

Ao aplicar o questionário e de posse dos dados, foi possível, embasado em teorias, desenvolver um texto reflexivo, analisando quais crenças são mais evidentes sobre a profissão de professor de Língua Inglesa da citada instituição. A próxima seção se ocupará de mostrar e analisar esses dados à luz das teorias apresentadas nos subitens anteriores.

\subsubsection{Reflexão teoria $x$ prática}

Como os teóricos afirmam e também como o pesquisador já suspeitava, muitas crenças sobre o ensino de Língua Inglesa podem auxiliar o trabalho do professor, mas outras configuram-se como um dos difíceis obstáculos para a completa profissionalização do acadêmico nos dias de hoje. Por isso, o professor precisa estar devidamente instrumentalizado para conseguir auxiliar o aluno em múltiplos contextos. De acordo com Ianesko (2013, p. 127),

[...]. É de se esperar de um professor, tanto da educação básica, média ou superior, a consciência de que ele é um dos responsáveis por ajudar a construir no aluno/indivíduo formas específicas de ler o mundo, os outros e a si mesmo e, talvez, observando as crenças dos alunos, assim como o contexto e história de cada um, auxilie nesse processo de ensino/aprendizagem.

Mas não se pode deixar de lado a grande dificuldade que um profissional do magistério tem enfrentado nos últimos tempos e que vai além da profissionalização: a falta de respeito e de condições básicas de trabalho. Muitos teóricos e pensadores da educação de todas as instâncias vêm alertando, ao longo do tempo, para a gama de desafios que esse profissional tem enfrentado, mas, mesmo assim, ano após ano mais e mais alunos ingressam nas universidades com o firme propósito de se tornarem professores, mesmo sabendo das dificuldades que os esperam.

É o que também mostram as respostas ao questionário, mais especificamente as da primeira pergunta: Como você tem visto sua futura profissão? Nove entre 15 alunos responderam quase que a mesma coisa, ou seja, que esperam conseguir, com a profissão, 
melhores condições de vida para eles e suas famílias. Um total de $60 \%$ dos entrevistados enfocou os desafios da profissão no cenário local e nacional, enquanto $40 \%$ disseram ter uma visão mais otimista do futuro e das condições profissionais do professor.

Gráfico 1 - Respostas dos alunos do curso de Letras da UEG, campus Jussara, sobre sua futura profissão

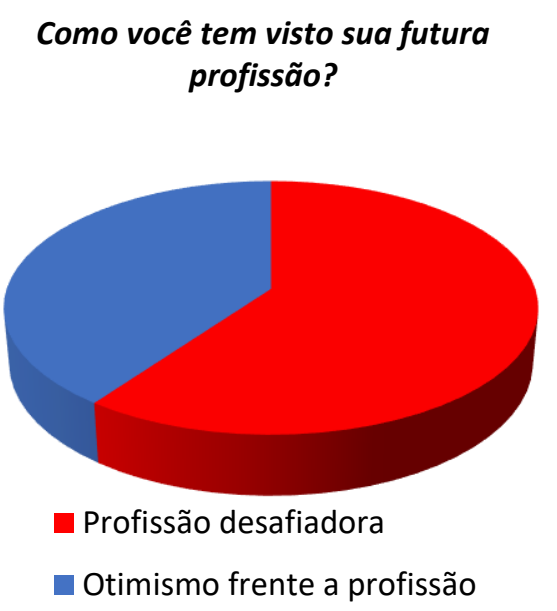

Fonte: Elaborado pelo autor, com base nos dados colhidos durante a pesquisa.

As respostas dos nove alunos à primeira questão, nas quais enfatizam a esperança de que a profissão poderá melhorar suas condições de vida, foram as seguintes:

Vejo essa profissão como sendo uma das mais desafiadoras, mas também como sendo a possibilidade que eu tenho para poder um dia dar uma vida melhor para minha família. (Aluno 01)

Profissão difícil devido às dificuldades que um professor enfrenta em sala, mas, entre as profissões que temos por aqui, é a possibilidade de mudança de minha vida e de meus familiares. (Aluno 03)

Atividade difícil, mas pode ajudar-me a melhorar de vida. (Aluno 06)

Embora seja uma profissão desvalorizada pelo poder público, mas pode ajudar-me a ajudar meus familiares no futuro. (Aluno 08)

Professores são pouco valorizados, mas é a minha possibilidade de mudar de vida. (Aluno 09)

Gosto de ser professor e sei que irei, com essa profissão, ajudar meus pais. (Aluno 10)

Profissão pouco valorizada, mas posso com ela ajudar minha família a viver melhor. (Aluno 12)

Profissão com péssimas condições de trabalho, mas é melhor que ser balconista. (Aluno 13) 
Profissão linda, mas desafiadora. Vejo nela a possibilidade de melhorar de vida. (Aluno 15)

Já à segunda pergunta - Você se sente preparado para ensinar Língua Inglesa? -, somente três (3) alunos respondem que sim, e quando indagados por que se sentem preparados, responderam da seguinte forma:

Sou autodidata e aprendi o máximo que pude em casa, assistindo séries, fazendo traduções de livros e sei que estou preparado, pois eu estudo na universidade e em casa e preparo para isso. (Aluno 04)

Sim, eu estou preparado, pois tenho feito as disciplinas de forma criteriosa e acho que tenho condições de ensinar. (Aluno 06).

Eu estou preparada, pois já morei um bom tempo fora do país e domino de forma sistemática a fala e escrita do inglês. (Aluno 07).

Os demais alunos acreditam que, embora sabendo que serão habilitados para ensinar a língua inglesa, precisarão fazer cursos extras para sentirem-se mais seguros em sala de aula. Comparando as respostas dos alunos 04 e 07, nota-se que o primeiro parece agir de forma mais empírica, enquanto o segundo apoia-se na crença de que sua vivência fora do país, embora enriquecedora, e pode contribuir para a prática diária de sala de não pode ser considerada como elemento primordial para sua motivação para aprender e para ensinar a Língua.

Quanto à terceira pergunta - Quais crenças você acha que possui em vias de terminar a faculdade? -, as respostas foram variadas, mas 87,7\% dos entrevistados acreditam que o curso de idiomas irá ajudá-los ao findar a licenciatura. Acreditam que, uma vez cursando inglês em uma escola de idiomas, conseguirão aprender a língua com mais facilidade, ser bons professores e preencher essa lacuna que acreditam estar aberta, mesmo que tenham quatro aulas de inglês por semana na UEG. Esses alunos também acreditam que com os estudos continuados em um curso fora da universidade conseguirão aprender o idioma com mais facilidade.

Gráfico 2 - Respostas dos alunos sobre suas expectativas para depois de formados 
Quais crenças você acha que possui em vias de terminar a faculdade?

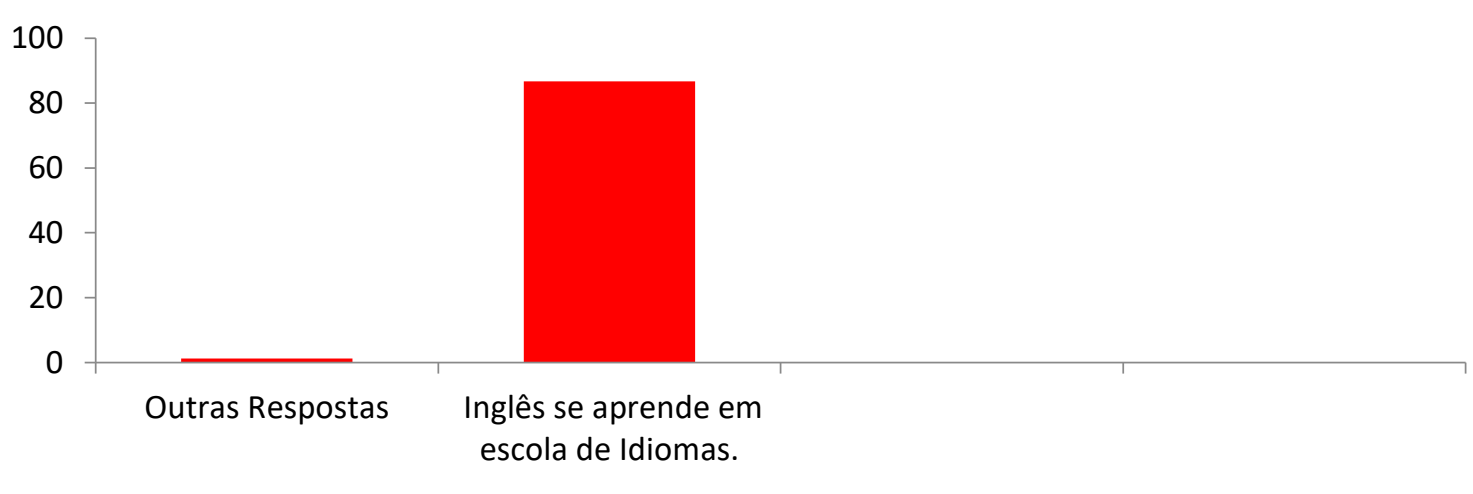

- Colunas 1

Fonte: Elaborado pelo autor, com base nos dados colhidos durante a pesquisa.

As respostas às quarta e quinta perguntas - O que é um bom professor de Inglês? e Como aprender Inglês de forma eficiente? - giraram em torno de assertivas do tipo:

O bom professor é aquele que ministra aulas usando o idioma que ensina. Aprender de forma eficiente é ter aulas motivadoras, com professores falando inglês o tempo todo e que proporcionem o uso constante das habilidades de ouvir, falar, ler e escrever, pois, se o professor não proporcionar contexto de uso, os alunos não aprenderão e questionarão as razões de se aprender esse idioma. (Aluno 01)

Sabe, às vezes eu questiono as razões para se aprender esse idioma, pois estamos tão distantes do contexto de uso do mesmo. Mas, enfim, para mim, o bom professor é aquele que compreende as limitações de seus alunos, está sempre motivado e faz aulas pensando em nossas dificuldades. Aprender de forma eficiente é aprender para o uso cotidiano. (Aluno 02)

O bom professor é aquele que está sempre motivado e flexibiliza os conteúdos para todos acompanharem as aulas. Aprender de forma eficiente é quando se utiliza mais a fala em sala, pois agindo assim o aluno começa a ver motivos para se aprender o idioma. (Aluno 03)

O bom professor é aquele cara camarada que sempre ajuda os alunos a aprender o conteúdo, por meio do lúdico, pois eu acho que distantes como estamos de contexto de uso, primeiro precisa se motivar, para depois inserir regras. Aprender de forma eficiente é saber falar a língua no final do curso. (Aluno 04)

Gosto de professores que são comprometidos e motivados com sua profissão. Aprender de forma eficiente é quando o professor utiliza jogos e brincadeiras, aproximando da vida real. (Aluno 05)

O bom professor não precisa planejar aulas, ele consegue fazer boas aulas, pois domina a língua. Aprender de verdade é quando se domina a língua e consegue falar com nativos, por isso, as aulas precisam ser em inglês. (Aluno 06) 
Professor precisa falar baixo e vagarosamente quando fala em inglês, pois ser fluente às vezes atrapalha, fala rápido demais, e se já não vemos muita razão para aprender a língua, se não conseguimos acompanhar fica ainda pior. Acredito que se aprende bem com boas viagens ao exterior. E todos devem usar a língua em sala o tempo todo. (Aluno 07)

Bons professores são os que não criticam seus alunos e fazem correção em particular. Aprender de forma eficiente é quando se entende as lições e pode usar bem o material didático. (Aluno 08)

Bons professores ministram aulas para todos, independentemente do desnível que encontra a sala. Aprender de forma eficiente é conseguir avançar cada dia um pouco. (Aluno 09)

Bom professor é aquele que devolve as atividades e faz correção em sala o mais breve possível. Aprender de forma eficiente é dominar o idioma, as aulas precisam ser em inglês. (Aluno 10)

O bom professor precisa ser motivado. Aprender de forma eficiente é ter competência frente à língua, por isso, é interessante que se tenha aulas no próprio idioma. (Aluno 11)

Bom professor é aquele que ensina por meio de figuras e mímicas. Aprender de forma eficiente é aprender todas as particularidades da língua. (Aluno 12)

Bons professores são aqueles que deixam claro o que os alunos irão aprender. Acredito que usando músicas podemos aprender de forma eficiente, pois podemos explorar o vocabulário e ouvir a pronúncia. (Aluno 13)

Gosto de professores motivados. Acredito que aprender inglês de forma eficiente é saber usar a língua, inclusive, para ministrar as aulas. (Aluno 14)

Bom professor se preocupa que tipo de aluno ele tem em sala e produz aulas pensando em seus contextos. Aprender de forma eficiente é saber usar a língua, por isso é importante ter aulas ministradas no idioma que se está aprendendo. (Aluno 15)

Gráfico 3 - Aspectos que os alunos consideram indispensáveis em uma aula de inglês 


\section{O bom professor}

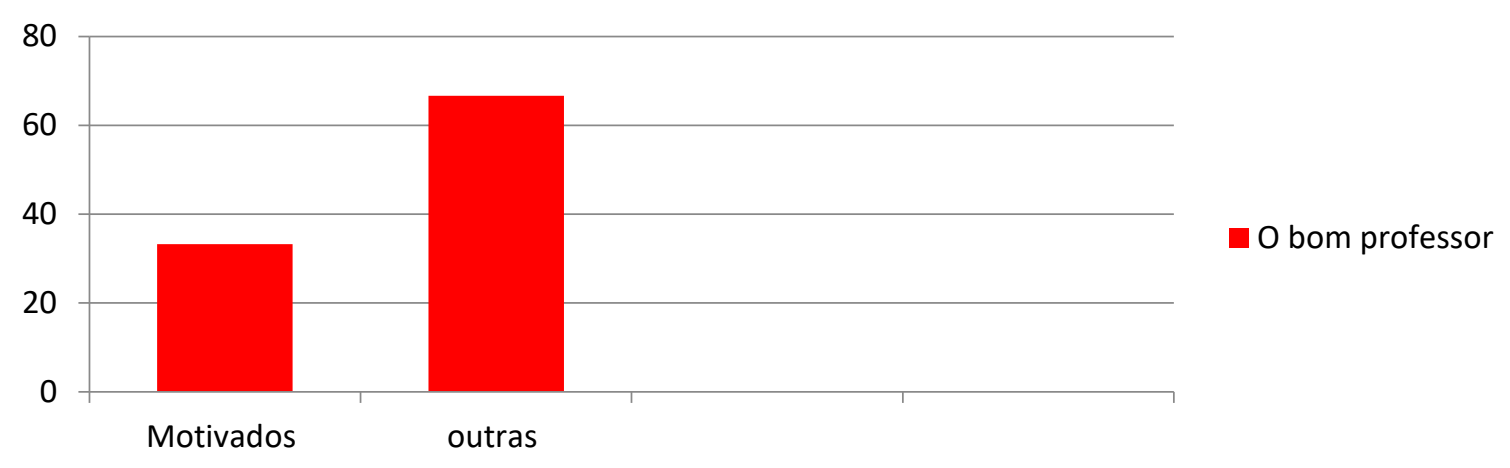

Aprender Inglês de forma eficiente

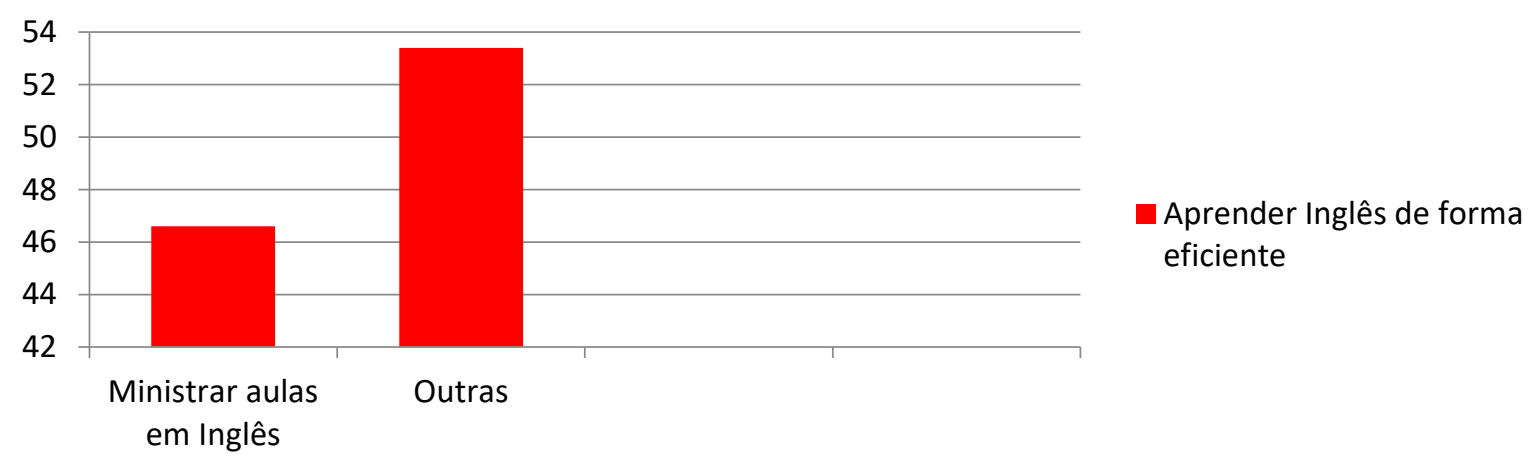

Fonte: Elaborado pelo autor, com base nos dados colhidos durante a pesquisa.

Conforme mostra o Gráfico 3, 66,7\% dos alunos entrevistados deram diferentes respostas à pergunta, todas baseadas nas crenças que possuem, mas, para 33,3\% deles, a motivação é a qualidade indispensável a um bom professor. Enquanto 46,6\% acreditam que se o professor usar a língua inglesa para ministrar as aulas eles conseguirão aprender com mais facilidade, os demais 53,4\% deram diferentes respostas. Observa-se um aspecto contraditório nas respostas dos acadêmicos que advogam aulas em inglês, já que admitem dificuldade de aprendizagem mesmo com as aulas sendo ministradas em português.

\section{Considerações finais}

O presente trabalho apoiou-se nas teorias de ensino crítico, crenças e identidade, dialogando com os principais teóricos, e buscou na prática empírica entender as concepções conjecturais que abordam as crenças de acadêmicos em vias de formação. Assim, trabalhou-se neste artigo com a ideia de que as crenças, em suas múltiplas acepções, podem causar um impacto significativo no trabalho do professor em sala de aula. É nesse sentido que Ianesko (2013, p. 117) afirma que "[...] todo relacionamento humano, para ser entendido, precisa ser 
observado através de aspectos como crenças e valores, entre outros”. Por isso, a pesquisa primou pela coleta de dados in loco, pois sabe-se que é impossível se chegar a um ponto comum senão pela análise da realidade circundante.

Com a realização deste trabalho, chega-se a conclusões interessantes sobre as identidades e crenças dos acadêmicos do curso de Letras da Universidade Estadual de Goiás (UEG), campus Jussara. Os 15 alunos que participaram da pesquisa parecem estar imersos em uma gama de crenças e, por meio da interação com os teóricos da Linguística Aplicada, foi possível entender que são elas que moldam a identidade de cada um dos participantes. Conforme Ianesko (2013, p. 127), “[...] a construção de significados e a construção da identidade dos alunos são também influenciadas pelo posicionamento de discurso do professor na escola e têm repercussão na forma de agir do aluno dentro e fora da sala de aula".

A maioria das turmas dos cursos oferecidos pela UEG é bastante heterogênea e com predominância sexo feminino. Esse é o caso da turma de concluintes do curso de Letras que constitui o universo da pesquisa, cujos sujeitos manifestaram diferentes posicionamentos sobre a prática docente. Os discentes são provenientes da própria cidade de Jussara ou de municípios circunvizinhos, e trazem para a sala de aula muito de suas vivências, aspirações, medos e angústias variadas. $\mathrm{O}$ que têm em comum é o fato de estarem todos em um mesmo cenário, em busca de um mesmo ideal. Embora em um primeiro momento pareçam ter posicionamentos distintos, no geral, todos querem alcançar sucesso quando no exercício da profissão que escolheram.

Apesar de as crenças parecerem estar camufladas, algumas ficam mais em evidência, por exemplo, a convicção de que em escolas de idiomas o ensino é mais eficaz; que o professor precisa ser motivado para ser considerado bom; ou que, para a aprendizagem da língua, o professor precisa ministrar aulas em inglês, dentre outras. Ao observar a vasta gama de respostas dadas ao longo dadas nos questionários, o que chama a atenção é que, embora algumas respostas sejam similares, o que se evidencia é a existência de um leque de expectativas e conjecturas sobre a futura profissão.

O que se observou com este trabalho é que, quando ingressa na universidade e ao longo de sua formação, o aluno tem preferido agir de acordo com suas intuições, e não fazendo uso das teorias propriamente ditas, o que leva a resultados não muito satisfatórios. Este trabalho vem ao encontro das necessidades que a escola hoje evidencia, pois, de acordo com Ianesko (2013, p. 126), “[...] sem educação de qualidade não se pode desenhar um futuro próprio e 
melhor, que motive os alunos a desejarem mais conhecimento e educação, e poder se desprender dos padrões que restringem o desenvolvimento humano em sua completude".

Em síntese, como foi discutido ao longo da pesquisa, o Brasil precisa avançar bastante no que tange a um ensino de qualidade para os alunos em suas várias instâncias. Por isso, a realização de pesquisas que vão a campo identificar os anseios dos alunos e professores pode ser um dos caminhos para a melhoria significativa do ensino e da aprendizagem de língua inglesa.

\section{Referências}

ALMEIDA FILHO, J. C. P. Dimensões comunicativas no ensino de línguas. Campinas, SP: Pontes, 1999.

BARCELOS, A. M. F. A cultura de aprender língua estrangeira (inglês) de alunos de Letras. Dissertação (Mestrado em Linguística Aplicada), Unicamp/IEL. Campinas, da Universidade Estadual de Campinas (Unicamp). Campinas, SP, 1995.

BARCELOS, A. M. F. Understanding teachers' and students' language learning beliefs in experience: A Deweyan Approach. Tese (Applied Linguistics). The University of Alabama, Tuscaloosa, AL, USA, 2000.

BARCELOS, A. M. F. Metodologia de pesquisa das crenças sobre aprendizagem de línguas: estado da arte. Revista Brasileira de Lingüística Aplicada. Viçosa, v. 1, n. 1, p. 71-92, 2001.

BARCELOS, A. M. F. A cultura de aprender língua estrangeira (inglês) de alunos de Letras. Dissertação (Mestrado em Linguística Aplicada), Unicamp/IEL. da Universidade Estadual de Campinas (Unicamp). Campinas, SP, 1995.

BENEVIDES, A. S. A leitura e a formação docente: a trajetória da prática da leitura de alunos/as do curso de Letras. Dissertação (Mestrado em Educação). Centro de Ciências Sociais Aplicadas da Universidade Federal do Rio Grande do Norte. Natal, 2005.

BENSON, P.; LOR, W. Conceptions of language and language learning. System, London. 27, n. 4, p. 459-472, 1999.

BREEN, M. P. The social context for language learning - a neglected situation? Studies in Second Language Acquisition. New York, v. 7, p. 135-158, 1999.

BURGEILE, O. Práticas educacionais no ensino de línguas e de literaturas. Florianópolis: Pandion, 2014.

CANDAU, V. M. Pluralismo cultural, cotidiano escolar e formação de professores. In: CANDAU, V. M. (org.). Magistério: construção cotidiana. Petrópolis, RJ: Vozes, 2008. p. 237- 
250.

CORACINI, M. J. A celebração do outro: arquivo, memória e identidade: línguas (materna e estrangeira), plurilinguismo e tradução. Campinas, SP: Mercado de Letras, 2007.

CUNHA, M. I. da. Reflexões e práticas em pedagogia universitária. São Paulo: Edições Loyola, 2007.

DEWEY, J. How we think. Lexington, MA: D.C. Heath, 1933.

FÉLIX, A. Crenças de duas professoras de uma escola pública sobre o processo de aprender língua estrangeira. In: ALMEIDA FILHO, J. C. P. (org.). O professor de língua estrangeira em formação. Campinas, SP: Pontes, 1999. p. 93-110.

HARMER, Jeremy. How to Teach English. Harlow: Pearson Education Limited, 1999.

IANESKO, R. A. Crenças e Estereótipos: O papel do professor nesse contexto. In: BURGAILE, O. Práticas educacionais no ensino de línguas e de literatura. Florianópolis: Pandion, 2013.

JOLY, A.; APARECIDA, A.; SANTOS, A. dos; SISTO, F. S. Questões do cotidiano universitário. São Paulo: Casa do Psicólogo, 2005.

LIBÂNEO, J. C. Democratização da escola pública. São Paulo: Loyola, 2006.

LIMA, D. C. de. Inglês nas Escolas Públicas não Funciona? Uma questão, múltiplas escolhas. São Paulo: Parábola Editorial, 2009.

MOREIRA, A. F. B; CÂMARA, M. J. Reflexões sobre currículo e identidade: implicações para a prática pedagógica. In: MOREIRA, A. F. B.; CANDAU, V. M. (org.). Multiculturalismo: diferenças culturais e práticas pedagógicas. 2.ed. Petrópolis, RJ: Vozes, 2008.

NÓVOA, A. Relação Escola - Sociedade: novas respostas para um velho problema. In: SERBINO, R. V. et al. (org.) Formação de professores. São Paulo: Fundação Editora da Unesp, 1998. p. 19-39.

NUNAN, D. Learner-centered English Language Education: The Selected Works of David Nunan. London: Routledge, 2000.

PEIXOTO, M. do C. de L. Universidade e Democracia: experiências e alternativas para a ampliação do acesso à universidade pública brasileira. Belo Horizonte: Editora UFMG, 2004.

RAJAGOPALAN, K. O conceito de identidade em linguística: é chegada a hora de uma reconsideração radical? Tradução de Almiro Pisetta. In: SIGNORINI, I. (org.). Lingua(gem) e Identidade: elementos para uma discussão no campo aplicado. Campinas, SP: Mercado de Letras, 1998.

SILVA, K. A. da. O futuro do professor de língua inglesa no espelho: crenças e aglomerados de crenças na formação inicial. In: BARCELOS, A. M. F.; ABRAHÃO, M. H. V. (org.). 
Crenças e ensino de línguas: foco no professor, no aluno e na formação de professores. Campinas, SP: Pontes, 1994. p. 105-124.

SILVA, I. M. Percepções do que seja ser um bom professor de inglês para formandos de Letras: Um estudo de caso. Dissertação (Mestrado em Estudos Linguísticos). Universidade Federal de Minas Gerais. Belo Horizonte, 2005.

SILVA, L. O. Crenças sobre aprendizagem de língua estrangeira de alunos formandos de Letras: um estudo comparativo. Dissertação (Mestrado em Estudos Linguísticos). Universidade Federal de Belo Horizonte. Belo Horizonte, 2006.

SILVA, S. V.; FIGUEIREDO, F. J. Q. Erro e correção: as crenças de dois professores de escola pública e de alguns de seus alunos. Revista Brasileira de Lingüística Aplicada. Belo Horizonte, v. 6, n. 2, p. 113-141, 2006.

TEIXEIRA DA SILVA, T. Resenha do livro de: VIEIRA-ABRÃO, M. H. Prática de Ensino de Língua Estrangeira: experiências e reflexões. Revista do ISAT, v. 1, n. 3, p.155-157, 2005.

TOTIS, V. P. Língua Inglesa: Leitura. São Paulo: Cortez, 1991.

VEIGA, I. P. A. A Prática pedagógica do professor de didática. São Paulo: Ática, 1989.

WHITE, C. Expectations and emergent beliefs of self-instructed language learners. System, New York v. 27, n. 4, p. 443-457, 1999. 